\title{
SMEs creativity and smart regional development
}

\author{
Claudiu Pirnau*, Daniel Ghiculescu and Niculae Ion Marinescu \\ Politehnica University of Bucharest, Department of Manufacturing Engineering, 313 Splaiul \\ Independentei, sector 6, Bucharest, Romania
}

\begin{abstract}
The paper presents new methods of smart regional development, starting from a question and one answer: How do we go about building our local smart ecosystem? Make one step at a time. This step is achieved through a number of seven elements: the SMEs network, the relations between universities and the labour market, the efficient using of transport infrastructure, the interactions specific to the various forms of capital with accent on intangible assets, smart relocation, online and offline interactions in smart communities, the used of young staff as a source of creativity and innovation, oriented to smart specialization, leading to sustainable competitive advantage.
\end{abstract}

\section{Introduction}

Large companies have research-innovation departments based on the development of creativity in specific areas: smart sales, smart hotels, smart cars, IoT, etc. In this context, the creative thinking is built with the help of specialized individuals, referred to as "intrapreneurs" [1]. As for SMEs, the creative development within the knowledge based economy must answer a set of four questions.

Question 1: Do SMEs have time to be creative?

Small entrepreneurs generally have a misconception with respect to creativity: this phenomenon is specific to large companies [2]. This conception prevents the identification and transformation of interesting ideas into commercially viable solutions. In the absence of encouragement for creativity and innovation by entrepreneurs, this culture will disappear. Employees of SMEs need time and space to think creatively and to turn their innovative activities into reality [3].

Question 2: Are there any obstacles that block ideas before they are creatively expressed?

In all small businesses, there are various such obstacles: disorder, disruptions, lack of planning, bureaucracy, and cash flow related problems etc. [4].

Question 3: What if?

The only task of SMEs that are integrated in networks belonging to an innovative environment is to create and implement futuristic innovations that should answer question 3 [5]. In these networks, programs can be introduced in order to give employees time for innovative activities of any kind (technological, business, etc.). This "innovation time" may range from 10 to $20 \%$ of a week's work schedule, depending on the characteristics and complexity of specific activities $[6,7]$.

\footnotetext{
${ }^{*}$ Corresponding author: claude.pyr@gmail.com
} 
Question 4: What are the sources of learning entrepreneurship?

For young people, there are four favourable environments to build this knowledge: the family environment (if possible), the educational, the entrepreneurial and the natural environment (with respect to market) [8,9].

The implementation of a creative culture in a creative environment developed in a certain time of innovation leads implicitly to the creation of smart SMEs that meet the new requirements of the knowledge-based economy.

\section{Smart SMEs Network}

The development of a network / cluster requires the existence of a regional environment with strong links between sectors.

Smart regional development implies efficient and constant interactions between the SME network and regional communities. An entrepreneur has to switch from between a business model and a business plan.

The cluster management must first adopt a certain model (e.g. Triple helix, Four clover or Five for all etc.), and then take into account the specificities of locally existing offline communities (smart community, creative bio-community, etc.).

As the knowledge based economy has been developed on the basis of the digital economy, clusters cannot function without the new business instruments, and online communities.

A 2014 Demand Metric report shows that two-thirds of the companies use one of the four types of online communities: Social Communities, Support Communities, Advocate Communities and Insight Communities [10]. The options for selecting the cluster type and the related communities are shown in Figure 1.

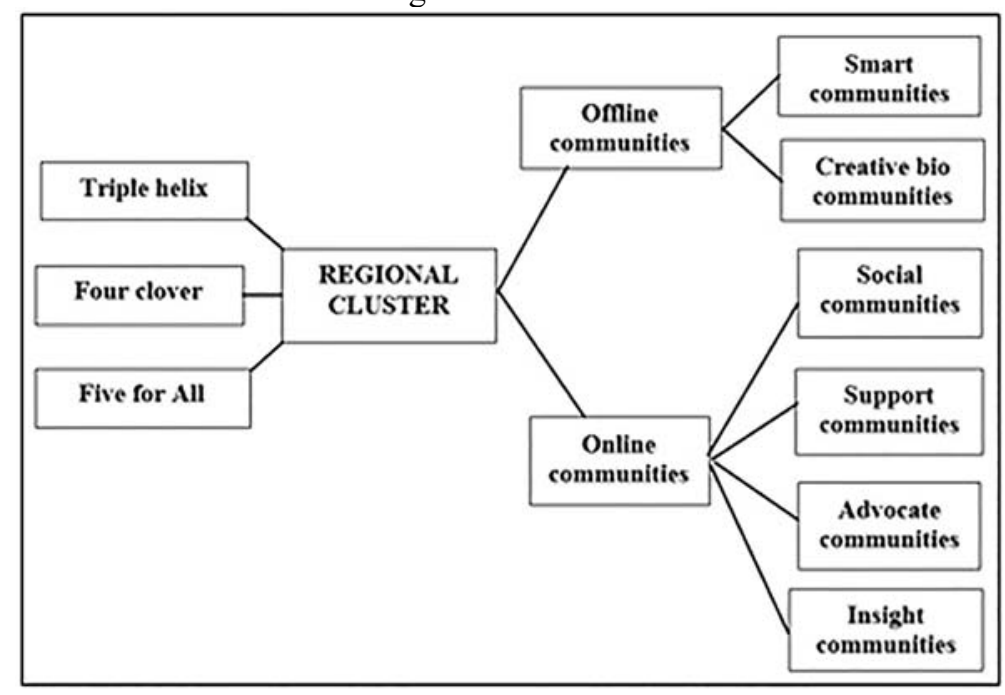

Fig. 1. Clusters and communities types.

In the knowledge based economy, economic opportunities are increasingly linked to the mobility (smart relocation) of people, goods and information.

\section{Online and offline interactions in smart communities}

The regional clusters development is based on interactions between smart SMEs (Cloud Computing; 5G Convergent Technologies; Big Data; Gaming and gamification; System 
abilities, SME \& benchmarking actions, safety certification e.g) and smart specialisation (ex ante conditionality for European Structural and Investment Fund support) [11].

In 2016 the European Commission launched three H2020 ICT Calls for proposals: supporting ICT transfer to the European creative industries, boosting synergies between artists, creative people and technologists and Gamification in different areas [12].

Considering the aspects mentioned in Chapter 2 hereof and starting from the List of selected projects H2020 - New projects supporting the Creative Industries and Gamification, we notice that 182 projects having as main object of activity "Digital Single Market" are approved.

This data distribution is graphically represented in Figure 2. It can be noticed that the share of projects having "Universities" as beneficiary is about $10 \%$.

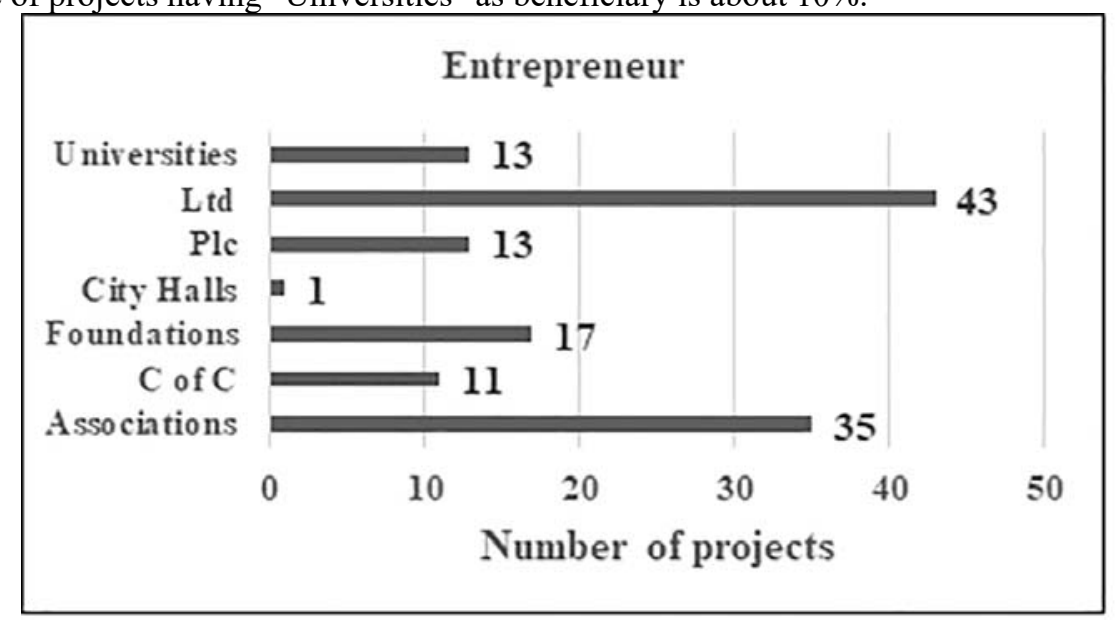

Fig. 2. Project distribution.

If we are interested in following the variation of the absolute frequency of projects in the categories specified, they are illustrated in Figure 3.

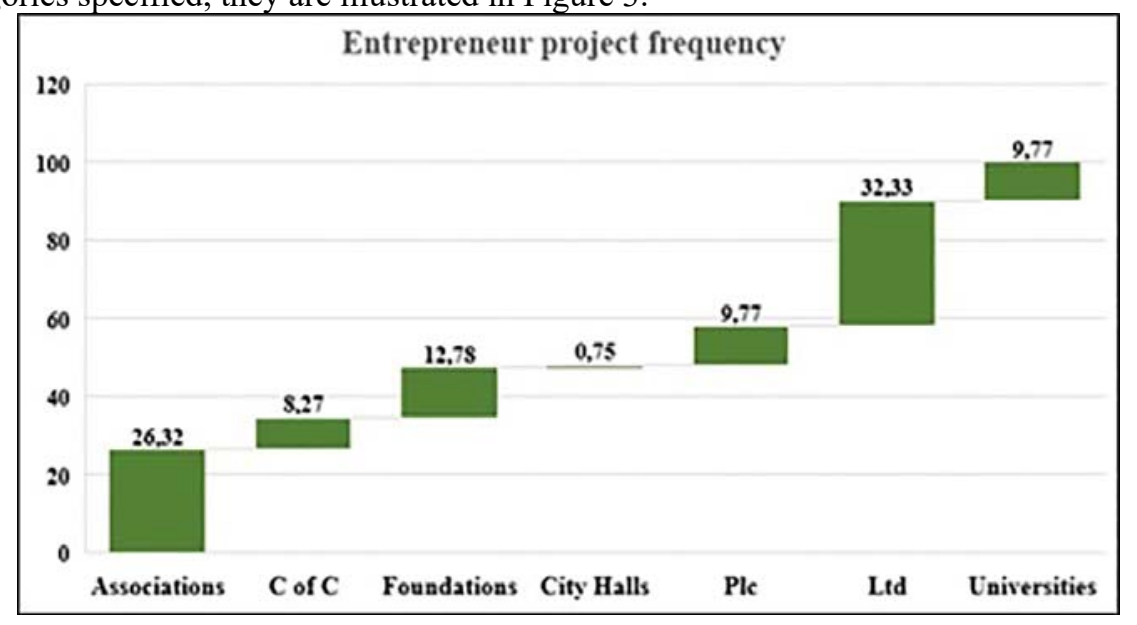

Fig. 3. Absolute project frequency.

In the Table 1, we have three types of Specific Group Applicants: Associations, Foundations \& Universities (AFU), Public and Private Limited Companies (Plc \& Ltd) and Chambers of Commerce \& City Halls.

In this case, we notice that the share of projects for the AFU group is about $50 \%$. 
Table 1. Groups types.

\begin{tabular}{|c|c|c|}
\hline Type & Entrepreneur & $\begin{array}{c}\text { Absolute } \\
\text { frequency }\end{array}$ \\
\hline Associations + Foundations + Universities & 65 & 48,87 \\
\hline Plc + Ltd & 56 & 42,11 \\
\hline Chambers of commerce (C of C) + City Halls & 12 & 9,02 \\
\hline
\end{tabular}

The absolute frequency specific to projects grouping in Table 1 is shown in Figure 4.

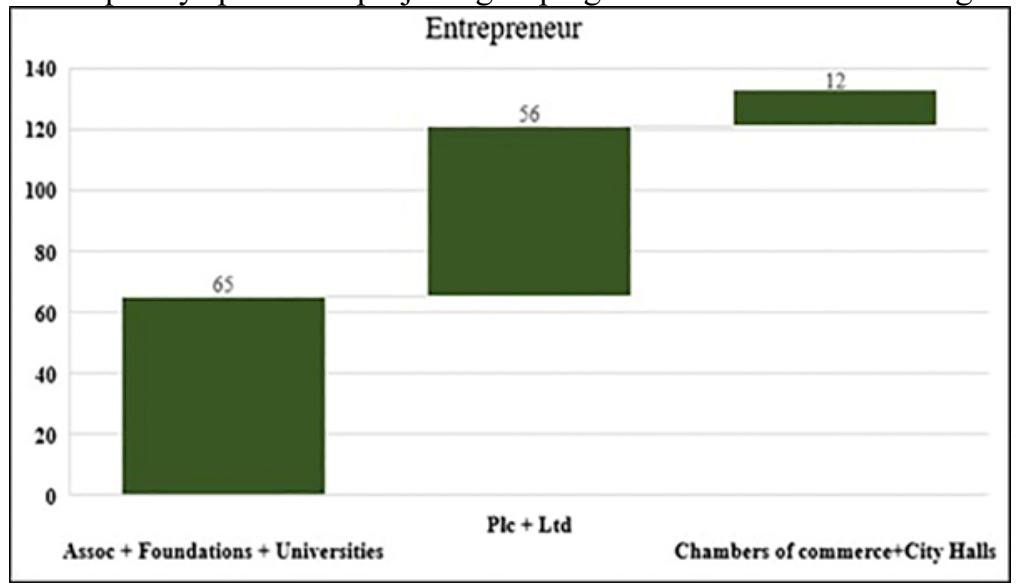

Fig. 4. Absolute project frequency (from Table 2).

The absolute frequency values for start-up projects are shown in Table 2.

Table 2. Start-up projects absolute frequency.

\begin{tabular}{|l|c|c|}
\hline \multicolumn{1}{|c|}{ Type } & Start-up & Absolute frequency \\
\hline Associations & 14 & 28,57 \\
\hline Chambers of commerce & 7 & 14,29 \\
\hline Foundations & 7 & 14,29 \\
\hline Institute & 4 & 8,16 \\
\hline City Halls & 1 & 2,04 \\
\hline Ltd & 10 & 20,41 \\
\hline Universities & 6 & 12,24 \\
\hline
\end{tabular}

The specific project distribution and the absolute frequency values (by single or groups of applicants), visualize and manage the complex clusters development by considering the interactions between entrepreneurship, smart SMEs, universities, public administration and smart communities.

\section{Intangible assets and Sustainable Competitive Advantage}

Sustainable competitive advantage (SCA) is the basis for major economic performances for any enterprise, regardless of the field in which it activates, but it becomes essential in smart specializations, where the creativity, and the dynamics of development are critical. The process of SCA achieving based on intangible assets (IA) is synthesized in Figure. 6. 


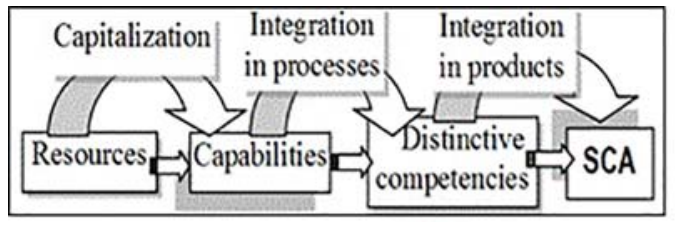

Fig. 5. Model of SCA obtaining based on intangible resources.

In this context, we proposed an aggregate mark of indicators $\left(N_{i a}\right)$ related to IA evaluation of SMEs that can be calculated using the following relation [13]:

$$
N_{i a}=\sum_{k} c_{k} * w_{k}
$$

Where: $c_{k}$ is the coefficient corresponding to indicator $k(0$ or 1$) ; w_{k}-$ the weight assigned to indicator $k$; the assigned weights fulfils the condition: $\sum w_{k}=100 \%$. In Table 3 , a proposed list of indicators for evaluation of IA is presented with weights applicable high-tech areas.

Table 3. List of indicators for intangible assets evaluation that could lead to SCA (extract).

\begin{tabular}{|l|c|}
\hline \multicolumn{1}{|c|}{ Indicators for intangible assets evaluation } & $\begin{array}{l}\text { wk } \\
\text { [\%] }\end{array}$ \\
\hline Detail knowledge of specific needs of customers & 3 \\
\hline Capacity of integration in customers processes & 2 \\
\hline Capacity of offering complete solutions to customers & 6 \\
\hline Capacity of maintaining a permanent contact with customers & 3 \\
\hline $\begin{array}{l}\text { Capacity of orientation to new markets, on which customers demand customized } \\
\text { products }\end{array}$ & 3 \\
\hline Capacity of forming companies networking, clusters, virtual organizations & 6 \\
\hline $\begin{array}{l}\text { Enough diversification for compensation of decline on a certain market segment and } \\
\text { enter another one with greater opportunities }\end{array}$ & 4 \\
\hline Capacity of abroad expansion & 4 \\
\hline $\begin{array}{l}\text { Capacity of implementing permanent improvement programs of products quality and } \\
\text { costs decrease }\end{array}$ & 4 \\
\hline Capacity of focusing on strongly customized products & 3 \\
\hline Capacity of focusing on markets with high potential of growing & 3 \\
\hline Total weights assigned to indicators & $\mathbf{1 0 0}$ \\
\hline
\end{tabular}

The proposed evaluation has the advantage that provides evaluation and ranking though aggregate marks on the scale $0-100$, which is very visible, offering to SMEs a tool for their efficient development. The smart SMEs would then be in a much better position to answer the following key questions: What are my key intangible assets?; How do I create and maintain sustainable competitive advantage (SCA) using my intangible assets?; What are the drivers of value for my intangible assets?; Which key performance indicators (KPIs) should I use to manage my intangibles?; How do I mitigate risks to my intangibles?

\section{Conclusions}

Universities play a vital role in entrepreneurial ecosystems. The resources, the young labour force and its training in university centres altogether represent an attraction for entrepreneurs and investors.

Entrepreneurs can attend formal or informal meetings, workshops, may be members of specific associations, or may attend training courses. These forms of organization have the greatest impact when entrepreneurial density is relevant in that geographic area. Developing a creative entrepreneurship leads to increased welfare of a region / community. 
The results are reflected in quantitative and qualitative improvements in human capital as well as physical capital, such as utilities, transport or telecommunications infrastructure. Development can only be achieved in the context of the interdependence between the two forms of capital. Infrastructure cannot function effectively without maintenance; whereas economic activities cannot take place without proper infrastructure.

The projects carried out by means of smart communities must cover a long-term commitment regarding resources availability, predictability and credibility of creative SMEs, with innovations manifested both in technical and managerial sides. This is the main source of sustainable competitive advantage, which is based on owning intangible assets.

The Knowledge SMEs Management should be considering the intangible assets within potential targets and the financial impact of proposed acquisitions thoroughly during due diligence, so that they are able to answer any probing questions from analysts and stakeholders effectively.

Intangible assets, therefore, provide sustainable competitive advantage, but as assets they clearly demand smart and creative management.

\section{References}

1. M. Marchese, J. Potter. LEED WPS, LEEDP, OECD Final Report (2010)

2. M. Mrva, P. Stachová. Procedia - SBS 110, 617-626 (2014)

3. R. Florida, FDHVE. Carnegie Mellon University, USA (2002)

4. *** PG ERDF MA. European Commission, Belgium (2012)

5. C. Pirnau, M.A. Titu, L.I. Rosca, M. Pirnau. PISC SAMRO, Technical Publishing House, 224-231, Bucharest (2016)

6. M.J. Waits. CDIR, Federal Reserve Bank of San Francisco, USA (2015)

7. *** ARMGOEOLSC. Regional Technology Strategies Inc., USA (2013)

8. A. Tripon. PSBS 188, 330-334, Elsevier Ltd. (2015)

9. T. Howard, S. Culley, E. Dekonink. PICED, Paris, France (2007)

10. https://www.visioncritical.com/types-of-online-communities-best-practices/

11. https://ec.europa.eu/digital-single-market/en/news/new-projects-supporting-creativeindustries-and-gamification

12. *** GS HSSMEPSF, European Commission, Belgium (2016)

13. V. Vulturescu et al. NTR 14, 117-122 (2014) 